\title{
TEXTO DE UN EXILIADO MORISCO EN TÚNEZ (SIGLO XVIi)
}

Por

HEDI OUESLATI

Este texto, aunque pertenece a un manuscrito inédito, puede considerarse como una reedición, porque ha sido copiado y editado por otros caminos.

En 1933, Jaime Olver Asín utilizaba esta narración sobre el exilio morisco y la instalación de los exiliados en Túnez, a partir del manuscrito S. 2 de la Colección Gayangos, de la Biblioteca de la Real Academia de la Historia, de Madrid (1). Su trabajo, que ha sido estudiado desde entonces por todos los investigadores de los moriscos, se tradujo al francés y se editó en 1973 (2). Por esa misma fecha, Henri Piéri volvía a editar la traducción francesa del texto del manuscrito S. 2 (3), que había publicado en Túnez en 1968 (4). La totalidad del manuscrito S. 2, del morisco tunecino, parece va a ser editado en fecha próxima por Álvaro Galmés de Fuentes y Luce López-Baralt (5).

En relación aún no bien explicitada con el autor del texto y el ms. S. 2, el P. Francisco Ximénez, Trinitario y Director del Hospital de los cristianos en Túnez, leyó, transcribió y utilizó este texto durante su estancia en Túnez (6). Mercedes García Arenal ha editado recientemente un nuevo texto inédito de Francisco Ximénez que se inspira del relato del morisco exiliado $y$ se conser-

(1) "Un morisco tunecino admirador de Lope. Estudio del Ms. S. 2 de la Colección Gayangos", Al-Andalus, Madrid, 1, 1933, 409-450

(2) "Un morisco tunisien, admirateur de Lope. Etude du Ms. S. 2 de la Collection Gayangos", en M. de EPALZA - R. PETIT, Receuil d'études sur les Moriscos Andalous en Tunisie, Madrid, 1973, 205-239

(3) "L'acceuil par les Tunisiens aux marisques expulsés d’Espagne», EPALZA - PETIT, o. c., 128-134.

(4) Id., IBLA, Túnez, 121, 1968, 63-70.

(5) Ver L. LÓPEZ-BARALT, Huellas del Islam en la ilteratura española. De Juan Ruiz a Juan Goytisolo, Madrid, 1985, p. 254.

(6) Ver M. de EPALZA "Nuevos documentos sobre descendientes de moriscos en Túnez en el siglo XVIII", Studia Historica et Philologica in honorem M. Batllori, Roma, 1984, 195-228; "Nouveaux documents sur les Andalous en Tunisie au début du XVIliè siècle». Revue d'Histoire Maghrébine, Túnez, 17-18, 79-108; S. M. ZBISS - A. H. GAFSI - A. BOUGHANMI - M. de EPALZA. Etudes sur les Morisques Andalous, Túnez, 1984, 57-90, 67-70. 
va en la traducción inédita en castellano de Budinar. Historia de Túnez, conservado también en la Biblioteca de la Real Academia de la Historia (7).

El texto que aquí se va a presentar es también de Francisco Ximénez, del manuscrito titulado Diario de Argel, t. Ill, Biblioteca de la Real Academia de la Historia, E. 195, folios 199-207. Coincide totalmente con los fragmentos del manuscrito S. 2. Hay que atribuirle por tanto a la misma fuente, copiada por la pluma atenta y minuciosa del P. Francisco Ximénez, siempre interesado por los hispanos y los andalusíes en el Mágreb, tal y como aparece en el diario de sus 18 años de estancia en Orán, Argel y, sobre todo, Túnez (8). En su diario tunecino, exactamente el día 22 de octubre de 1724, hace una mención expresa de un fragmento de este texto, con la advertencia: "Oygase lo que dice un autor moro anónimo en un libro en lengua española» (9). Es esta voz del morisco exiliado de España e instalado en Túnez la que se expresa en el siguiente texto.

"De más de ésta, procuravan los christianos arbitrios para acabar con esta nación mahometana, viendo que no se podían conducir sus corazones firmes en la fe cierta a su diabólica secta. Unos decían fuesen muertos todos. Otros que fuesen capados. Otros que les diesen un botón de fuego en parte de su cuerpo, para que con él no pudiesen engendrar y fuesen muriendo con que se consumiría, como si pudieran deshacer lo que estaba determinado en la eternidad de Dios Nuestro Señor.

Y por estas causas estávamos de día y de noche pidiendo a Nuestro Señor nos sacase de tanta tribulación y riesgo, y deseávamos vernos en tierra del Islam, aunque fuera en cueros. Y junto con esto se procura una vía y modo para salir, y todos los caminos los hallávamos dificultosos, hasta que el poderoso Señor con su Misericordia puso en el corazón del tercero Philipo $y$ en los que eran sus consejeros que mandase saliésemos de su reyno con pena de la vida, y nos abrió los caminos por la mar y por la tierra, libres y sin daño, pues mandó nos acompañasen gente de ellos, para quitar lo que podía ofrecerse, saliendo en navíos por la mar y en carroza por la tierra, con hijos, mujeres, hacienda, y nos trajo en tierra del Islam. Los loores a su divina grandeza.

En ésta nos recibieron Uzmán Dey, rey de Túnez, de condición sovervia, y para nosotros manso cordero, Sidi /f. ${ }^{\circ} 200 /$ Vulgaiz con su santidad y la gente con su Islam, y todos procurando acomodarnos, y regalándonos con grande amor y amistad. Uzmán. Dey quitó una costumbre que avía que pagar cada vagel que al puerto llegava cien escudos por la entrada, fundado en que se animasen a traernos a esta ciudad, y junto con esto, nos dio a escoger

(7) "Nota a las traducciones manuscritas de F. Ximénez en la Real Academia de la Historia", Al-Qanțara, Madrid VI, 1985, 525-533

(8) Ver H. OUESLATI, "Argel, según el diario inédito de Francisco Ximénez (1718-1720), Sharq Al-Andalus Estudios Árabes, Alicante, 3, 1986, 169-181.

(9) M. de EPALZA, "Nuevos documentos...", p. 221-222 
el poblar en partes diferentes. Los que escogieron la Mahdía fue contra su gusto, y con todo esto los ayudó con trigo, cebada y escopeta, y no tuvo efecto, donde se conoció su buen celo y voluntad. Ésta la tuvo de que fuese en los lugares que oy son, acudiendo y favoreciendo con grande valor. Y supe de un íntimo amigo suyo, que quando estava enfermo, dijo "En levantándome con salud hemos de ir tú y yo a todos estos lugares y mirar lo que les falta y dárselon. Y les dio tres años de libertad que no pagasen nada, y otros indicios de su buen celo y amor que nos tuvo. El fue quien hizo saix, y el que quiso que no se metiese nadie con nosotros y éramos favorecidos con grande estremo, y decía que éramos genízaros sin paga, y particularidades que por ser muchas dejo de decir.

Sidi Vulgaiz por su parte acudía con sustento y acomodarlos en las zaguyas de la ciudad, y entre ellas en la de Sidi El Zulaychi adonde estavan con sus mujeres y hijos mucha gente pobre, y como es ordinario los muchachos ensuciarse, sin saver dónde lo hacen, lo hicieron / f. ${ }^{\circ} 201 /$ en ésta con estremo hasta que el guaquil de ella dio noticia a Sidi Vulgaiz, y encareció estar hecha un muladar. A que respondió "Déjalos estar, y que se ensucien, y hagan lo que quisiere, que si el lugar donde está supiera hablar, dijera: Sea muy en hora buena venidos a mi dichoso sitio la venturosa gente y los perfectos muslimes y queridos hermanos, a quien no amarán ni querrán sino el que fuere mumin, y no los aborrezerá sino el que fuere munáfiq."

Este santo hombre, antes que sailese la multitud de nosotros, dijo a los primeros que acá estavan cómo todos avíamos de salir de poder de los herejes, honra con que Dios lo honró, y descubrió, y así nos esperaba con tanto gusto $y$ contento, $y$ acudió a favorecernos con todas veras, y otras cosas, que no me acuerdo aora de ellas, y éstas las digo porque no se acaben de olvidar, pues mientras vivían los que venimos no se olvidavan, pero ya con el discurso del tiempo que se van acabando lo refiero, para que los que an nacido acá lo sepan de mí, y de los pocos que quedan y sepan y reconozcan, que Dios nuestro Señor nos sacó de entre los infieles como tengo referido, y que el hacerlo fue grande ventura y dicha, que nos alcanzó de que devemos estar agradecidos y no ser ingratos, como lo fueron los hijos de Israil, que los sacó del poder de Faraón, el que hacía con ellos tantos insultos y menosprecios, apremiándolos a lo que no podian llevar, y les envió por Capitán al Santo profeto Muza y su hermano Harun, y con su favor los sacó, y llegando al mar dio con su vara, y les abrió doce caminos desviándose las aguas a una y otra parte, y pasaron por tierra enjuta de la otra parte, y quando vino /f. ${ }^{\circ} 202 /$ Faraón en su seguimiento con doscientos mil soldados al entrar en los caminos se juntaron las aguas, y los anegó el Criador, librando a su pueblo, y dándole el sustento del cielo en maná y prometiéndoles llegarían a la tierra de promisión, libres y sin detrimento, y con todo esto fueron tan desagradecidos que adoraron al becerro con cuya causa fueron malditos cavendo sobre ellos la maldición de Dios, y la desdicha, que desdichados viven $y$ en tormento estarán en el otro mundo sin Redempción, ni remedio. 
Y nosotros, las alabanzas a su divina grandeza, nos sacó de poder de Faraones y malditos herejes inquisidores, y sin abrirse la mar nos trujo a la tierra deseada, adonde fuimos bien recibidos y hospedados, que aunque al vulgo hallamos ser algunos facinerosos avía muchos santos y hombres justos que de serlo todos, les sobrepujáramos según el celoy deseo que trahíamos, pero hasta que esta fue culpa nuestra, a seguir a lo que no fue justo, y basta que de qualquiera suerte oymos en altas vozes las palabras de la Unidad, que tan oculta la decíamos y basta que venimos a profesar, y mostrar la ley de Dios, y al obrar cada uno mire lo que le está bien, como se dirá en adelante en este libro con el favor de Dios.

Todo este discurso, queridos amigos y hermanos, he traido para dar a entender, que el aver venido al Islam a sido obra milagrosa de Dios; pues dejando de mirar su poder y voluntad, veíamos mucha dificultad en nuestra salida, y pues la facilito por camino tan fácil, no ay duda que somos favorecidos de su divina grandeza como lo fueron /f. ${ }^{\circ} 203 /$ los hijos de Israil, y aquéllos con tener a los santos profetas delante y a nosotros con sólo ser de la Uma dichosa de su más querido bastó usar de la Misericordia que usó y misma que nos dio, y así tenemos obligación muy grande, los que lo vimos de estar de día y de noche agradecidos y los que no lo vieron lo hechen de ver también con tan buena información, $y$ qe lo sean con más estremo, pues ellos fueran los que más lo avían de padecer si allá nacieran, que ya los que eran presentes estavan arraigados en la fe, de suerte que aunque se viesen abrasar no se mudarían de su buen celo.

Después de muertos los que nos favorecían, se trocó el gobierno en otros, que aunque eran de la gente de aquel tiempo, se trocaron las intenciones, y creció en ellos la envidia, y fueron procurando innovar la estimación que antes teníamos, y comenzaron a hechar pechos aunque moderados, dejando entre nosotros el gobierno, $v$ éste a durado hasta este presente tiempo, que se volvió a trocar, $y$ junto con estos muchos de nosotros trocaron el bien por los vicios, con que se renovaron los agravios y nuestra aflición, pero conviene tener el corazón firme en la grandeza de Dios, que pues nos sacó de tantos trabajos, y nos trujo a donde publicássemos su santa ley, y nos honra con tan grande bien, confiemos en su misericordia que es cierta señal de que nos tiene aparejada su santa gloria, y descanso después de tantas persecuciones que tubimos, y nos enbía, pues no las da sino a sus queridos, y permitiera con su divina piedad, que sean para descuento de las culpas y peccados, que sin razón cometemos, que mirando que todo viene /f. ${ }^{\circ} 204 /$ que todo viene de su mano, hecharemos de ver que como señor absoluto y criador de sus criaturas y gobernadores, tiene sus corazones en su mano, y que nos suelta a que nos hagan injurias sino por la desobediencia, que tenemos en cometerlos, y que es con piedad, pues es sólo en las haciendas no en las personas, y en éstas no an de poder nacer más de lo que fuere justo, porque quien tiene tan bueno defensor como su divina grandeza, y el auxilio de nuestro querido profeta y que nos trajo al Islam con tanta facilidad y nos dictan buen suerte y ventura, no puede criatura humana ofendernos y si lo hace a de ser para más premio nuestro porque la fe y crehencia verdadera es imposible que ellos 
la perturban, como no pudieron los que tan oprimidos nos tubieron, y con este bien nos basta.

Y assí, queridos hermanos, sólo encomiendo la conformidad y amitad entre todos, porque amados y conformes sirva de fuerte muro con pedir juntos al criador nos libre de quien injustamente nos quiera ofender, y que sea sin presumir mal ni poder loco unos de otros, antes aunque se vea cosa al parecer no ser justa se comente con amor y afabilidad en que es bien con la mejor comentación que se pueda, porque no upedo persuadirme, que nadie quiera el daño para su misma sangre y nación, que sólo es presumpción de quien aborrece o embidia. En el discurso de este tratado se verá lo que en esto hacian los santos hombres y seguidores de nuestro profeta, para que se tome ejemplo en ello y se heche de ver /f. ${ }^{\circ} 205 /$ lo bien que a uno le está llevar las cosas por camino que le libre de caer en pena esté su corazón limpio y puro con todos los muslimes, no presumiendo de ninguna cosa mala porque estando de esta suerte será de los que albrició nuestro Profeta con la gloria, como assí se verá en este libro.

De mucha importancia ubiera sido después de aver venido al Islam, que se usase de la humildad, per Luzbel, apetito, mundo y vanidad no dieron lugar a tanto bien, antes incitaron a que se mostrasen las galas y bizarrías, que quando se vino no avía ni mostrasen las galas y bizarrías, que quando se vino no avía ni las conocían, hasta que están oy en alto estado, que se pueden comparar a las grandezas de los grandes particularmente en los adornos de las mujeres, pues cada una lleva más oro, que otras tienen de caudal en las tiendas más ricas, y es la suerte de las mínimas se adornan con cosas que las reinas de esta tierra no llevaban antes de nuestra venida.

Y no an dejado estas cosas de hacernos daño, pues la envidia es un venenoso animal, que siempre está gruñendo, hasta que derrama su veneno, $y$ éste mata sin sentir al envidiado. El alcanzar estas riquezas es mejor que sea para gozarlas en la gloria con adquerir lo contrario de lo que en este mundo se adquiere para el mismo mundo, y allá las ay rodando y sin perturbación eternamente. Aquí lo verás curioso lector y queridos hermanos y amigos, advirtiendo que el bien o el mal, que al más mínimo le deseo, venga en mis ojos, $y$ en cosas más, con que quiero que estéis satisfechos de mi voluntad, y buenos deseos, y ruego a nuestro Señor humildemente nos junte en su santa gloria, por $/ f .^{\circ} 206 /$ su misericordia y intercesión de su más querido profeta, luz y norte que nos guía a ella." HASTA AQUÍ EL AUTOR DICHO. 